\title{
The Role of Brand Image Orientation, Innovativeness and Sustainability Marketing Commitment on Company Performance: Moderating Influence of Sustainable Leadership
}

\section{Poomthan Thaenthao}

Purdue University, USA.

Email:Poomthan.th@purdue.edu

\begin{abstract}
Sustainable marketing commitment of the organization could lead them towards high performance and gained top management and researchers' attentions. Thus, the current study also examines the role of brand image orientation and innovativeness on sustainable marketing commitment. The goal also includes the moderating role of sustainable leadership among the nexus of brand image orientation, innovativeness and sustainable marketing commitment. This study also examined that impact of sustainable marketing commitment on the performance of mobile phone companies in Thailand. This study has followed the quantitative methods such as questionnaires for the data collection and analyzed the data with smart-PLS. The researchers have adopted the mail and personal visit methods to send surveys to the selected respondents. A total of 550 questionnaires were forwarded to the respondents and received only 340 after fifteen days of distribution and has a response rate of 61.82 per cent. The results exposed that brand image orientation and innovativeness have a positive association with sustainable marketing commitment. The results also indicated that sustainable leadership significantly moderates among the links of brand image orientation and innovativeness on sustainable marketing commitment. The outcomes also show that sustainable marketing commitment has a positive impact on firm performance. These outcomes are suitable for policymakers who want to develop sustainable marketing commitment and firm performance policies.
\end{abstract}

Keywords: Brand image orientation, Innovativeness, Sustainable leadership, Sustainable marketing commitment.

JEL Classification: Q56; Q55; M31.

\section{Introduction}

The marketing world has revolutionized a lot in the recent decade. The notion to increase productivity in terms of profit only is the talk of the previous century. In the modernized world, sustainable development and productivity options are considered as one of the strongest drivers of a firm`s overall performance and well-being. Brand image is described as the consumer`s perception about the specific product in the market and is totally based on the interaction between customer and firm`s representatives (Ishaq \& Di Maria, 2020). In developed countries like the USA, brand image orientations have successfully blended with the sustainable development goals. Sustainable development goals are the essence of the creation of a soft image of different brands in the world. In Argentina, a company named Tom`s shoes was created recently and this company has the vision to eradicate poverty. This company provides shoes to needy children. They provide one pair of shoes to the needy children on the sale of one pair of shoes. This type of optimistic approach can make this world a better place for living. Brands should create eco-friendly products to enhance the life and sustainability of this planet. Companies all over the world have re-formulated their marketing strategies for the betterment of their performance in terms of the creation of sustainable product manufacturing pathways. The innovative and well-equipped manufacturing units to create desired products are frequently used in the new business ventures to support the environmental sustainability goals of the companies (Lesmana, Widodo, \& Sunardi, 2020).

Product manufacturing cycles are the basic frameworks that define the company`s love for the environment. The modern-day manufacturing units are quite different from the previous ones in terms of operations and overall processing. Effluent generation is lethal for the health of the environment and all its inhabitants. Solid and liquid wastes are a source of harmful chemicals and pollutants. Proper manufacturing cycles that generate a minute amount of waste are essential for environmental sustainability. The novel and innovative approaches to cope up with all the imminent hazards in terms of habitat destruction and climate change are essential to maintain good marketing practices. The market value of a firm is enhanced when they use simple and bio-degradable raw material for product manufacturing cycles (Khan et al., 2020). When companies include sustainability as their prime goal for the betterment of the human race and the health of the environment then their business excels promisingly. Companies all over the world have banned the use of plastic bags because they are non-biodegradable as a gesture to inculcate the love of nature in their consumers. This is a sweet and innovative gesture which not only supports 
environmental sustainability but also economic sustainability (Sule \& Onuoha, 2020). Climate change and poverty are the main driving forces that have revolutionized the overall scenario of marketing practices all over the world.

Leadership is the only solution to all the practical implementation of innovation and critical control challenges in the way of sustainability. Leaders are the guiding stars of the nation. They instigate a sense of corporate social responsibility in their sub-ordinates. All strategies of innovation, planning, brand equity, and sustainable development of a company are highly dependent on the management and leadership practices. Leadership can make a perfect blend of innovation, cultural diversity, and sustainable development. Modern firms all over the world have made their agendas based on leadership management practices. When leaders make their availability necessary to inculcate the sense of sustainable development then results are really tremendous. Leaders should act on the PPP principle and this principle defines the importance of three major pillars of business and society i.e. people, planet, and profit (Lăzăroiu, Ionescu, Andronie, \& Dijmărescu, 2020). All these pillars form the base of organizational sustainability. The developed countries like the USA, have initiated the US aid program to make this planet a more beautiful place to survive. The government has already started efforts to formulate strategies that can withstand the present hazards of climate change (Fonsén \& Soukainen, 2020). Wall mart is a tremendous store in the USA, and they have clearly mentioned on their website about the SDG goals. Such type of innovative and novel marketing strategies can surely fulfill the requirements of sustainable market commitment.

Sustainable market commitment is a novel strategy to make a promise with your consumers that you will invest more time and money for the sustainable development of the environment and market (Moktadir et al., 2020). There are several ways to improve the company`s performance is the generation of a complete roadmap for communication. This communication platform should announce the company`s sustainable development strategies to the consumers. Reduction of energy consumption is imperative to make the environment sustainable. An example of a sustainable marketing strategy is a grocery store (Brookshire Grocery company). This company has reduced its fuel consumption tremendously and they have created a whole page on their official website to educate their consumers about the importance of sustainable marketing strategies. The advertisement campaigns should launch to educate the employees as well as consumers about the company`s sustainability policies. The CEOs and other professionals should have great communicative efficacy (Sudusinghe \& Seuring, 2020). Effective communication is imperative for the prosperity of the company. Companies should indulge themselves in the reduced, reuse, and recycle policies to get funding from international funding organizations. This is the best way to produce effective and fruitful results. In the developed countries the manufacturing plants have totally changed and are replaced by modernized units of production. These units use less electricity and fuels and produce economically and environmentally sound products in relatively short intervals of time (Alcaide, De La Poza, \& Guadalajara, 2020).

A company`s performance is the parameter of its success in the business community. Brand image and interactions between the company`s representatives and the general public are useful for the prosperity of organizations. The last decade has highlighted climate change and degradation of the global atmosphere (Agustine, Etty, \& Wayan, 2020). Global warming, habitat destruction, and ozone layer depletion are some of the harmful consequences of this climate deterioration. Honest and diligent efforts from all of the departments are required for the well-being of the environment and its inhabitants. The business community should also understand the importance of environmental protection and at the end of the $20^{\text {th }}$-century efforts were started to cope up with environmental destruction on a global scale. Huge business companies have put environmental sustainability. The economists have formulated new and innovative policies to cope up with the modern trends and imminent dangers. Reduction of waste generation and fuel consumption are considered vital efforts for sustainability development. One example of the fuel usage reduction is of Toyota Company. They introduce care named Prius that has very low fuel consumption. Such initiates not only make a company`s performance good but also generate a level of respect and confidence between consumers and companies. Companies' agendas and long-term goals must include green manufacturing and marketing initiatives. These initiatives produce a low amount of waste products and can make the environment sound for each and every creature of nature.

The main objective of this research paper is to elucidate the correlation between important market drivers like brand image orientation, sustainable leadership practices, innovativeness, and sustainable marketing commitment efforts. The previous researchers have done a lot of work on all these aspects separately as the main drivers of successful business ventures but the literature was unable to provide any strong evidence about the positive or negative correlation between all these variables and a company`s performance. Sustainability and corporate social responsibility efforts are essential for the environmental and social wellbeing of the company. So, it is imperative to highlight the important aspects of sustainable marketing strategies in terms of brand image orientation and all other sustainable development and promotion based variables. Another aspect that was missing in the literature is the innovative strategies. All the previous researchers have talked about sustainability and environmental protection but they were unable to devise proper methods to build and create this global change. So, this paper will provide a deep insight into those novel strategies for the improvisation of the company`s performance.

Technological interventions in Thailand has brought forth promising future implications. In these specified industries the natural and environmental sustainability efforts have started when Thailand industries merged themselves with Huawei. The sustainable development goals are truly implemented in all the technical institutions. Thai industries manufacture mobile phones and computers in a technologically smart and eco-friendly manner. The whole scenario has changed a lot in the previous century. So, it is essential to provide consumers with a smart, efficient, and environment-friendly manner. The notion of Thailand industries is effective to produce safe sustainability practices. The future endeavors include producing techno-smart gadgets with zero biologically hazardous waste generation and recycling of all the waste with the green processing practice. All the other companies in the Thai technological hub are also thinking about the adoption of a different strategy. If all the processes are integrated in this way then the future will not only be economically stable but also provide social and environmentally stable products in the future.

Thailand, the second-largest economy in the ASEAN region, has changed its emphasis from a manufacturing economy to a digital economy, following the widespread of the internet and the Thai government's ambitious move 
towards digital development through Thailand's 4.0 initiative. Thailand's IT demand will rise by more than 13 percent year on year in 2019 and will be worth Bt527 billion by the end of this year. Hardware would be the largest contributor to Bt234 billion, while digital platforms would have the fastest growth rate of 34 percent. Smart gadgets, including CCTV and smart Bluetooth, are priced at about Bt121 billion or 23 percent of the overall IT industry. Software platforms will account for 20 percent of Bt106 billion and digital content would be priced at Bt65 billion, or 12 percent of the total IT industry. They would have an important part to play in marketing, advertisement, and product presentations. Thailand's networking industry is expected to cross THB 18.3 billion by 2025 from THB 10.7 billion in 2018 to CAGR 8 percent over the forecast era. Technology fields such as Big Data, IOT, Artificial Intelligence, Block chain, and $5 \mathrm{G}$ will be the main differentiators for Thailand's progress in the next decade. Table 1 has shown the country-wise ICT business share.

Table-1. Country-wise ICT business share.

\begin{tabular}{c|c|c}
\hline \multicolumn{3}{|c|}{ Table-1. Country-wise ICT business share. } \\
\hline Sr. & Country & Business \% in world Share. \\
\hline 1 & Thailand & 2 \\
\hline 2 & Malaysia & 2 \\
\hline 3 & Mexico & 2 \\
\hline 4 & Germany & 3 \\
\hline 5 & Singapore & 10 \\
\hline 6 & Japan & 11 \\
\hline 7 & Taiwan & 11 \\
\hline 8 & Korea & 19 \\
\hline 9 & USA & 32 \\
\hline 10 & China & 7 \\
\hline 11 & Rest of the World &
\end{tabular}

\section{Literature Review}

Brand image orientations are those indicators that provide essential insights to the company`s overall strategies regarding positive approaches to the environment and all its counterparts. The well-regulated and wellmanaged brands have a tendency to improvise the overall performance of the company. Brands' consciousness has been increased in the last few years. This attitude of consumers has put additional pressure on the community and business ventures to create products of high quality that are not only eco-friendly in nature but also economically sound. The biological non-degradable materials produced by the companies have produced many problems in recent years. People throughout the world are now more concerned about social and environmental well-being. The effluent wastewater produced by the industries is a source of pollution and is lethal for the well-being of the fresh and seawater inhabitants. In the modernized world, these notions are considered seriously. The product manufacturing pathways of all the industries are well-defined and in accordance with eco-friendly techniques. The wastewater and all the sludge from the industries are now treated with proper SOPs and innovative techniques for the protection of the environment. It is imperative for all the brands to advertise the eco-friendly procedures for the sustainable protection of nature and its resources. Brands' image orientation based on these precautionary measures makes the company more reliable for the consumer. They feel satisfied with the SOPs and well-defined marketing policies of brands. So brand image gets much better because of these innovative interventions. In the globalized network, the improved and sustainable marketing policies provide essential tools for the company`s overall prosperity of the business community. Competition between different brands provides huge benefits to excel in the lieu of sustainable environmental protection. A well-regulated framework of brand image orientation example is of Wall-mart international. This company has included in its agenda the sustainable developmental policies and they have instigated the corporate social responsibility innovations to the other brands as well.

H1: Brand image is positively associated with sustainability marketing commitment.

Innovative strategies that create biodegradable and environmentally sound products. The manufacturing units are based on the strategies to reduce, reuse, and recycle. The developed countries have seriously focused on green manufacturing processes. These processes are difficult to handle and require new and innovative machines that manufacture products at a very slow pace. In developing countries, people are unaware of the importance of a green economy and green manufacturing processes so they put the safety standards low. These companies in developing countries do not put ample effort and time into the manufacturing units to recycle and reuse things (Meuer, Koelbel, \& Hoffmann, 2020; Ren et al., 2020). No specific transparent and regulated processes are needed for the demand and supply chain manufacturing. So, they produce products at a very rapid rate. The design of sustainable product manufacturing cycles in developing countries is not up-to-date so they produce products with hazardous chemicals and biohazards based waste effluents (Soderstrom \& Weber, 2020). The developed countries smuggle things from the developing countries to meet the demand and supply gap. Innovative control and regulatory standards are necessary for the betterment of sustainable product manufacturing cycles (Silvestre \& Fonseca, 2020). Environmental protection and quality control departments improvised the security checking procedures and they have argued that product quality is described by its product manufacturing program (Hashom, Ariffin, Sabar, \& Ahmad, 2020). Organic tags and biologically degradable products are expensive to produce and expensive to deliver for the consumers but they are overall best for the health and well-being of not only humanity but also for the environment. Regulatory authorities must implement strict policies on all of the countries in the world to make this world a better place for living.

H2: Innovative is positively associated with sustainability marketing commitment.

Leadership is the essence of each and every operational unit. If the leaders are strong they can bring forth the team to marvelous heights. In the developed countries people are well-aware of the importance of a green economy and green manufacturing practices. They demand green manufactured products from the suppliers (Loza, 2020). They emphasize the use of biologically safe and sound materials for the well-being of the environment. The manufacturers and companies have transparent strategies and planning initiatives for the well-being of the 
environment in these countries (Jain, 2020). Sustainable product manufacturing cycles has put forth the world on the verge of new and innovative manufacturing and supply chain management phase. In developing countries, people are unaware of the green economy its benefits, and overall environmental protection protocols. They use substandard products and their leaders are corrupt. These corrupt people have made the whole humanity doubtful about the human ethics and behaviors. Proper training and guidance related protocols are necessary for the head of companies. They should guide their sub-ordinates to work on the PPP (People, Planet and Products) protocols.

H3: Sustainability leadership significantly moderates the relationship between brand image orientation, Innovative, and sustainability marketing commitment.

These two terms can be used interchangeably as the sustainability commitment is the essence of all the betterment of performance of all the countries. Developed countries have fulfilled the sustainable market commitment policies. In developing countries, the notion is quite vague and they tend to manufacture low-quality products (Elzarka, 2020). Check and balance and regulatory control practices are quite unknown in these countries so proper precautionary protocols are necessary for the betterment of their economy. Companies when work in a coordinated fashion then create eco-friendly and sustainable products. Industrialization is although a premium for modem development, yet its effects on surroundings are equally hazardous (Gold \& Taib, 2020). The input of the chemical industry to human wellbeing is apparent in the broad collection of chemicals used in drugs, cosmetics, plastics, paints, and many other consumer goods (Grewal \& Serafeim, 2020). Major effluents such as antibiotics, drugs, and heavy metals are carcinogenic, mutagenic, and teratogenic. Regrettably, all these hazardous wastes finish up in the environment (Hörisch, Wulfsberg, \& Schaltegger, 2020). Hazardous waste will be defined in general terms as waste that is likely to cause harm to the environment, regarding effects on health, surface water, soil, and biota (Qian, Tilt, Dissanayake, \& Kuruppu, 2020). Executives behave as though they have to choose between the largely social benefits of developing sustainable products or processes and the financial costs of doing so. But that's simply not true (Gazzola, Pezzetti, Amelio, \& Grechi, 2020).. Social media marketing trends are nowadays most rapid and easy way of mass awareness. So, companies should implement sustainable marketing strategies for the betterment of their operations in the long run (Aktaş, Kayalidere, \& Karğin, 2013). Leaders can control the whole organization and they can reshape the whole scenario. In the modern age, well-equipped and environmentally sound protocols are imperative for the generation of green products. Coordinated efforts from all of the departments are necessary for the improvement of the company`s performance (Lăzăroiu et al., 2020).

H4: Sustainable market commitment significantly mediates the relationship between brand image orientation, innovative and company's performance.

H5: Sustainable market commitment has a strong positive correlation with a company`s performance.

\section{Methodology}

The current study investigates the role of brand image orientation and innovativeness on sustainable marketing commitment. The goal also includes the moderating role of sustainable leadership among the nexus of brand image orientation, innovativeness and sustainable marketing commitment. This study also examined that impact of sustainable marketing commitment on the performance of mobile phone companies in Thailand. This study has followed the quantitative methods such as questionnaires for the data collection. The selling and marketing department employees of mobile phone companies in Thailand are the respondents of the study that are selected based on non-probability purposive sampling. The researchers have adopted the mail and personal visit methods to send surveys to the selected respondents. A total of 550 questionnaires were forwarded to the respondents and received only 340 after fifteen days of distribution and has a response rate of 61.82 per cent.

This study has analyzed the data with smart-PLS due to the study's large sample size and complex framework (Hair Jr, Babin, \& Krey, 2017). The constructs include two predictors named brand image orientation (BIO) with six items and innovativeness (INN) with five items. In addition, sustainable marketing commitment (SMC) is used as a mediating variable with seven items and sustainable leadership (SL) is used as a moderating variable with four items. Finally, company performance $(\mathrm{CP})$ is used as a dependent variable that has five items. The variables are shown in Figure 2 with relationships.

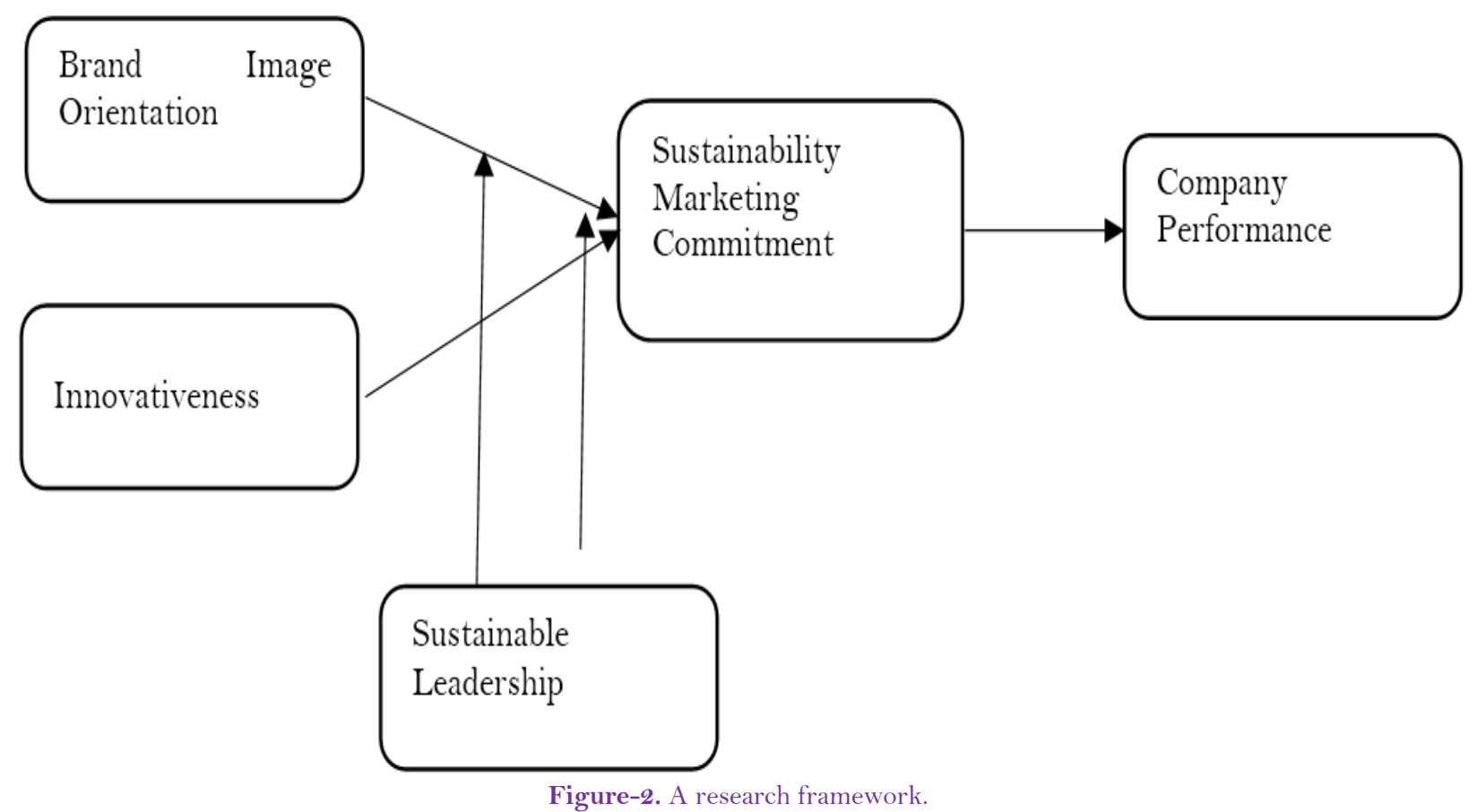




\section{Findings}

The present study outcomes show the validity such as convergent and discriminant validity and show the hypotheses testing. The convergent validity has been examined first. The figures show that high links among items and convergent validity are exposed as valid because the Alpha and CR values are higher than 0.70, and the figures of loadings and AVE are larger than 0.50. These values have been exposed in Table 2 and the loading values also mentioned in Figure 3.

Table-2. Convergent validity.

\begin{tabular}{|c|c|c|c|c|c|}
\hline Constructs & Items & Loadings & Alpha & $\mathbf{C R}$ & AVE \\
\hline \multirow[t]{6}{*}{ Brand Image Orientation } & $\mathrm{BIO} 1$ & 0.912 & 0.944 & 0.956 & 0.782 \\
\hline & $\mathrm{BIO} 2$ & 0.824 & & & \\
\hline & $\mathrm{BIO} 3$ & 0.903 & & & \\
\hline & $\mathrm{BIO} 4$ & 0.902 & & & \\
\hline & $\mathrm{BIO5}$ & 0.912 & & & \\
\hline & BIO6 & 0.849 & & & \\
\hline \multirow[t]{5}{*}{ Company Performance } & $\mathrm{CP} 1$ & 0.814 & 0.889 & 0.918 & 0.692 \\
\hline & $\mathrm{CP} 2$ & 0.817 & & & \\
\hline & $\mathrm{CP} 3$ & 0.854 & & & \\
\hline & $\mathrm{CP} 4$ & 0.811 & & & \\
\hline & $\mathrm{CP} 5$ & 0.862 & & & \\
\hline \multirow[t]{4}{*}{ Innovativeness } & INN1 & 0.957 & 0.966 & 0.975 & 0.908 \\
\hline & INN3 & 0.944 & & & \\
\hline & INN4 & 0.953 & & & \\
\hline & INN5 & 0.958 & & & \\
\hline \multirow[t]{4}{*}{ Sustainable Leadership } & SL1 & 0.885 & 0.845 & 0.820 & 0.537 \\
\hline & SL2 & 0.670 & & & \\
\hline & SL3 & 0.677 & & & \\
\hline & SL4 & 0.676 & & & \\
\hline \multirow[t]{6}{*}{ Sustainable Marketing Commitment } & SMC1 & 0.955 & 0.959 & 0.968 & 0.835 \\
\hline & SMC2 & 0.826 & & & \\
\hline & SMC3 & 0.953 & & & \\
\hline & SMC4 & 0.956 & & & \\
\hline & SMC6 & 0.825 & & & \\
\hline & SMC7 & 0.955 & & & \\
\hline
\end{tabular}

The outcomes of the current study have also shown the discriminant validity. The figures show that low links among variables and discriminant validity are exposed as valid because the ratios of Heterotrait Monotrait are lower than 0.85. These values have been exposed in Table 3.

Table-3. Discriminant validity.

\begin{tabular}{l|c|c|c|c|c}
\hline & BIO & CP & INN & SL & SMC \\
\hline BIO & & & & & \\
\hline CP & 0.548 & & & & \\
\hline INN & 0.492 & 0.436 & & & \\
\hline SL & 0.266 & 0.220 & 0.537 & & \\
\hline SMC & 0.890 & 0.535 & 0.504 & 0.259 & \\
\hline
\end{tabular}

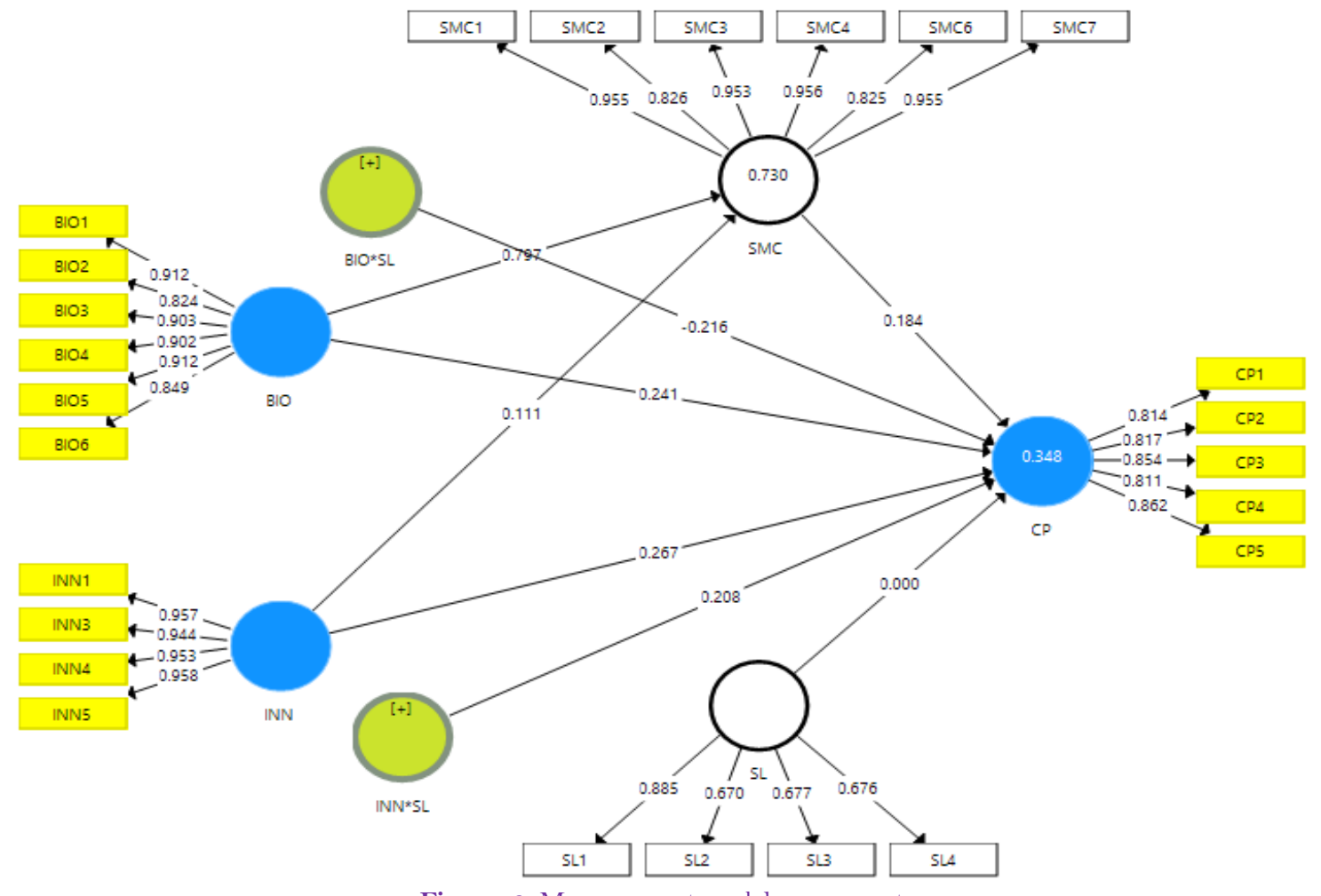

Figure-3. Measurement model assessment. 
In Figure 4 the results exposed that brand image orientation and innovativeness have a positive association with sustainable marketing commitment and accept $\mathrm{H}_{1}$ and $\mathrm{H} 2$. The results also indicated that sustainable leadership significantly moderates among the links of brand image orientation and innovativeness on sustainable marketing commitment and accept H3. The outcomes also show that sustainable marketing commitment has a positive impact on firm performance H5. Finally, the sustainable marketing commitment positively mediates among the nexus of brand image orientation, innovativeness and company performance and accept H4. These links are highlighted in Table 4.

Table-4. Path analysis.

\begin{tabular}{l|c|c|c|c|c|c}
\hline Telationships & Beta & S.D. & T Statistics & P Values & L.L & U.L \\
\hline BIO -> CP & 0.241 & 0.091 & 2.642 & 0.005 & 0.105 & 0.367 \\
\hline BIO -> SMC & 0.797 & 0.030 & 26.722 & 0.000 & 0.744 & 0.838 \\
\hline BIO*SL -> CP & -0.216 & 0.064 & 3.357 & 0.001 & -0.306 & -0.095 \\
\hline INN -> CP & 0.267 & 0.100 & 2.661 & 0.005 & 0.086 & 0.418 \\
\hline INN -> SMC & 0.111 & 0.041 & 2.725 & 0.004 & 0.050 & 0.173 \\
\hline INN SL -> CP & 0.208 & 0.086 & 2.428 & 0.008 & 0.051 & 0.344 \\
\hline SMC -> CP & 0.184 & 0.091 & 2.033 & 0.022 & 0.054 & 0.371 \\
\hline BIO -> SMC - > CP & 0.147 & 0.073 & 2.023 & 0.023 & 0.043 & 0.291 \\
\hline INN -> SMC -> CP & 0.120 & 0.053 & 2.264 & 0.024 & 0.012 & 0.246 \\
\hline
\end{tabular}

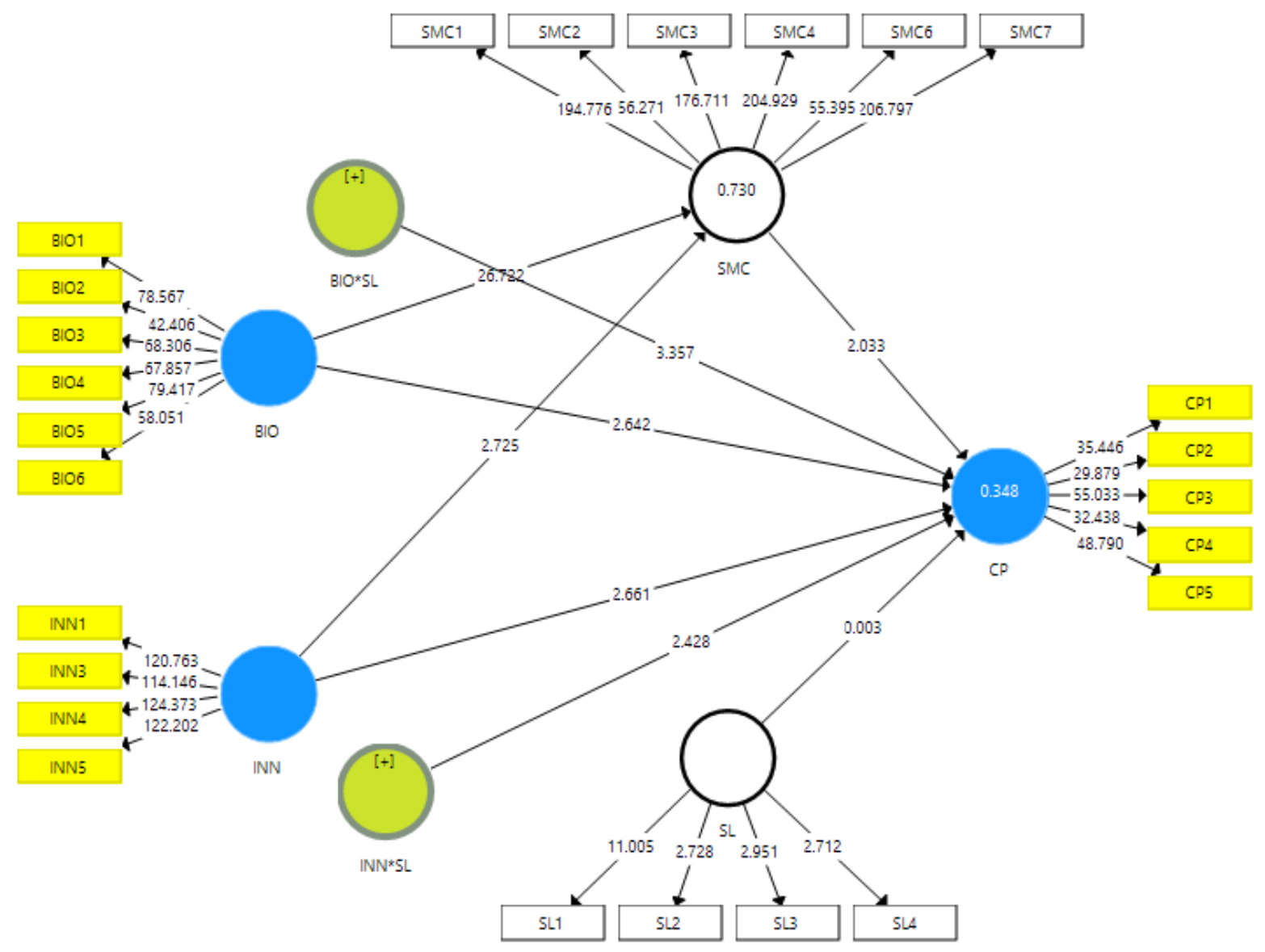

Figure-4. Structural model assessment.

The results in Figure 5 revealed that the sustainable leadership is negatively and significantly moderates among the association of brand image orientation and company performance and accept $\mathrm{H} 3$ because the blue line is above the red and green line. Figure 5 shows this relationship mentioned below:

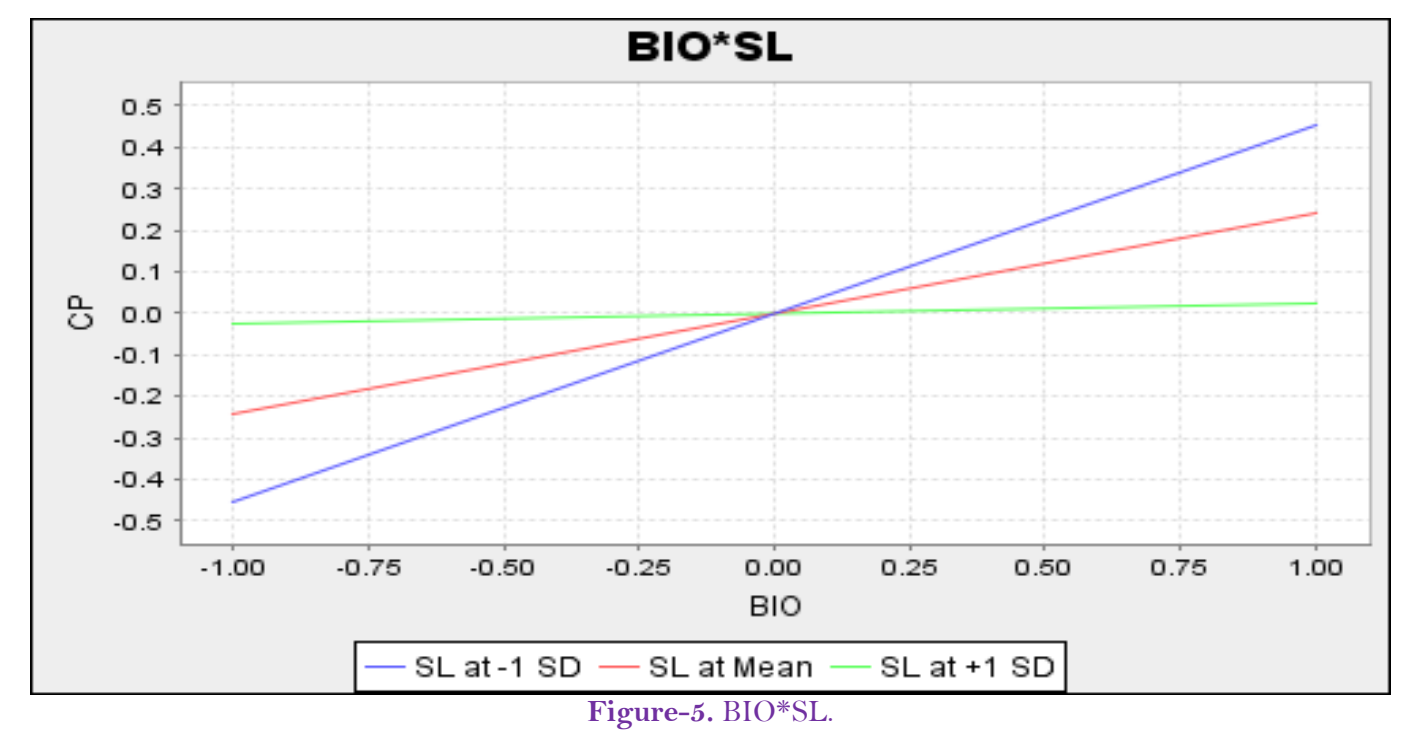


The results in Figure 6 revealed that the sustainable leadership is positively and significantly moderates among the association of innovation and company performance and accept H3 because the green line is above the red and blue line. Figure 6 shows this relationship mentioned below:

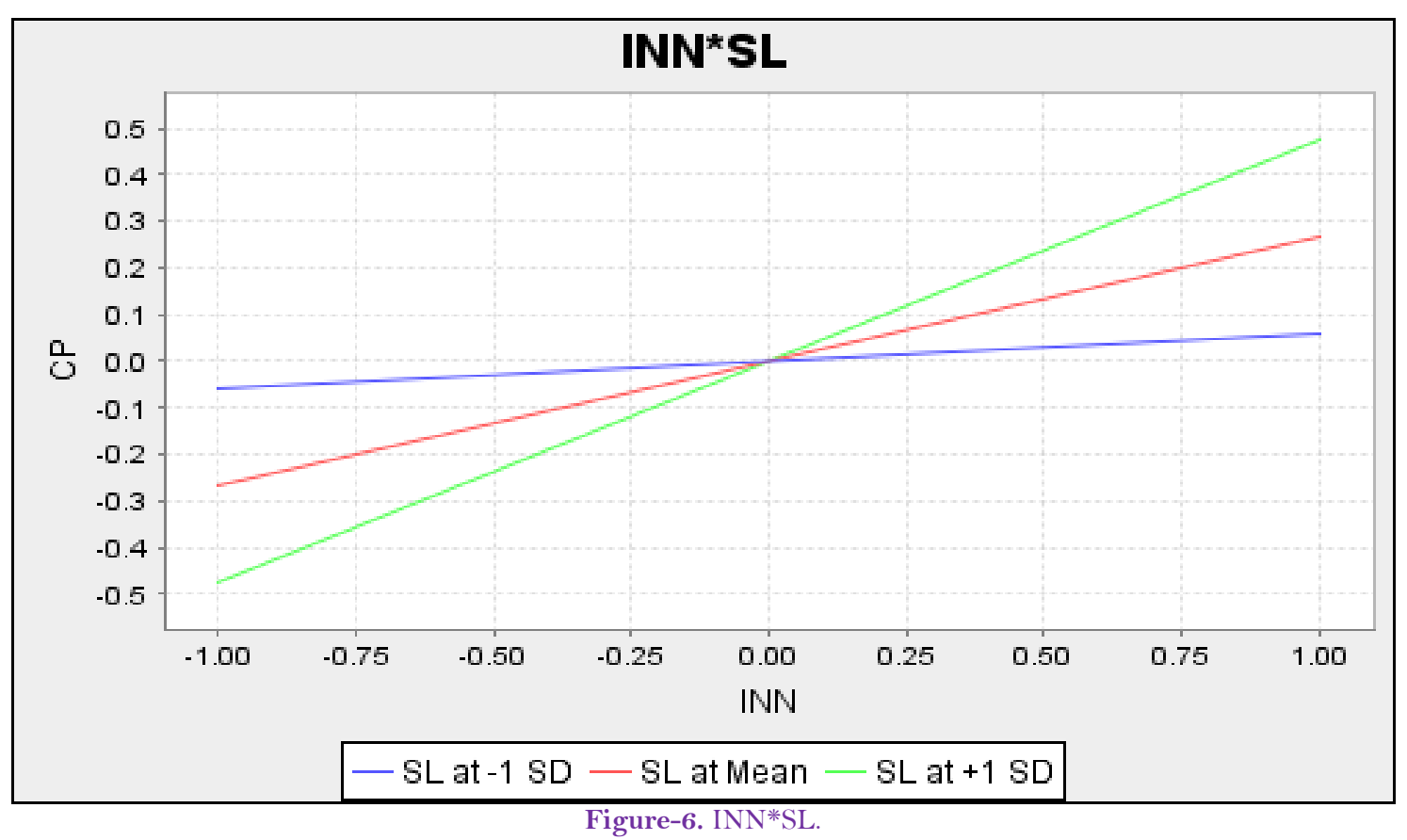

\section{Discussions and Implications}

The study results have revealed that the brand image orientation has a positive association with the development of sustainability in marketing commitment. The better the brand image orientation of a company, the better is the sustainability in the expression of a company's commitment to the market requirements. These results are in line with the past studies of Chang, Wang, and Arnett (2018) which suggest that the companies with a good brand image orientation at national and international markets are likely to have better marketing commitment. Thus, the sustainable well-known brand image orientation leads to sustainable marketing commitment. The study results have also shown that the innovativeness of the brand company has positive impacts on sustainable development in the company's marketing commitment. These results are approved by the studies of Bamgbade, Kamaruddeen, and Nawi (2017) which imply that the companies that care of the innovativeness of their operations, resources, and the products are expected to have sustainable development in their marketing commitment. The companies' performance of their functions according to the up-to-date market requirement and adoption of modern technology and techniques to keep the quality of their products innovative help develop sustainability in their marketing commitment. Our research findings have revealed that the sustainable marketing commitment of the companies has a positive association with the companies' performance. These results match with the studies of D'Agostini et al. (2017) which suggests that since the better sustainable commitment of the brand companies with the market trends and requirements motivate them to keep their operations smooth and innovative which enhances the companies' performance. These results have also revealed that effective sustainability leadership plays a moderating role between the brand image orientation and the development of sustainability in the companies' marketing commitment. These results are approved by the studies of Yahaya and Ebrahim (2016) which imply that the sustainable, effective leadership in the companies' operations improves both the sustainable brand image orientation and the companies' sustainable marketing commitment and the mutual association between the brand image orientation and the sustainability in the companies' marketing commitment. It's also been indicted by the study that sustainability in the effectiveness of leadership is a considerable moderator between the innovativeness of the companies' operations and production and their sustainable marketing commitment. These results match with the past studies of Afriyie, Du, and Musah (2020). These studies state that sustainability effective leadership improves the companies' innovativeness and sustainability in the companies' marking commitment, and thereby, it improves their mutual association. The study carries both the theoretical and an empirical implication. This paper has a profound theoretical significance because of its contribution to the literature on marketing management. This paper examines the sustainable brand image orientation and the companies' initiatives to bring innovativeness into their operations on the incorporation of sustainability into the companies' marketing commitment. It succeeds in gaining a distinction in the existent literature as it introduces both a mediator and a moderator at the same time. The sustainability in the companies' marketing commitment has been dealt with as a mediator between the brand image orientation, and the companies' innovativeness and their performance. The sustainability of efficient leadership has been addressed by this study as a moderator between the companies' brand image orientation, companies' innovativeness and the sustainability in their marketing commitment. The study has an empirical significance to the marking management of brand companies. It provides a guideline to marketing management on how to show higher sustainability into the companies' marketing commitment with better brand image orientation, innovativeness, and the sustainability in the leadership, and how to improve the companies' performance with higher sustainability in the marketing committee of the companies.

\section{Conclusion and Limitations}

The study has analyzed the companies' brand image orientation, and the companies' innovativeness in detail checks their relationship with the sustainability in the companies' marketing commitment. The sustainable, effective and highly preferred brand image orientation help the companies' to show sustainability development in 
the marketing orientation. Similarly, the high innovativeness in the companies' operations, the production, and marketing procedures and technology lead to the development of sustainability in the companies' marketing commitment.

The study has addressed the sustainability in the companies' marketing commitment as a mediator between the aforementioned variables and the companies' performance. The sustainability in the companies' marketing commitment is developed by the good brand image orientation and the innovativeness and in turn, improves the companies' performance. The sustainability in the effective and ethical leadership improves the companies' brand image orientation, companies' innovativeness and sustainable marketing commitment and their mutual association.

A number of limitations which are faced by the current study, despite the literary significance and its empirical implication, must be overcome by the scholars in future.

First of all, the current paper has a limited scope of the study as examines just two organizational factors like the brand name image and the innovativeness with direct relation to the sustainability in the companies' marketing commitment. Thus, future scholars are recommended to add to the number of indicators of sustainable marketing commitment. The empirical data has been extracted from the economy of Thailand, which is different from others in terms of culture, social, and economic conditions. Thus, the same study hypotheses are not equally valid to all the other economies. The future scholars are recommended to analyze the marketing commitment, and its constructors in more than one economy for better results and thereby, the validity of the study can be improved.

\section{References}

Afriyie, S., Du, J., \& Musah, A. A. I. (2020). The nexus among innovation types, knowledge sharing, transformational leadership, and marketing performance in an emerging economy. Journal of Indian Business Research, 12(4), 529-548.Available at: https://doi.org/10.1108/JIBR-03-2019-0082.

Agustine, D., Etty, M., \& Wayan, S. (2020). Analysis of water awareness, accountability, and governance to improve sustainability of firm's performance in urban areas. Geographia Technica, 5(1), 35-42.

Aktaş, R., Kayalidere, K., \& Karğin, M. (2013). Corporate sustainability reporting and analysis of sustainability reports in Turkey. International Journal of Economics and Finance, 5(3), 113-125.Available at: https://doi.org/10.5539/ijef.v5n3p113.

Alcaide, G., M. Á., De La Poza, P. E., \& Guadalajara, O. N. (2020). The impact of corporate social responsibility transparency on the financial performance, brand value, and sustainability level of IT companies. Corporate Social Responsibility and Environmental Management, 27(2), 642-654.Available at: https://doi.org/10.1002/csr.1829.

Bamgbade, J. A., Kamaruddeen, A. M., \& Nawi, M. (2017). Malaysian construction firms' social sustainability via organizational innovativeness and government support: The mediating role of market culture. Journal of Cleaner Production, 154, 114124.Available at: https://doi.org/10.1016/j.jclepro.2017.03.187.

Chang, Y., Wang, X., \& Arnett, D. B. (2018). Enhancing firm performance: The role of brand orientation in business-to-business marketing. Industrial Marketing Management, 72, 17-25.Available at: https://doi.org/10.1016/j.indmarman.2018.01.031.

D’Agostini, M., Tondolo, V. A. G., Camargo, M. E., dos Santos Dullius, A. I., Tondolo, R. d. R. P., \& Russo, S. L. (2017). Relationship between sustainable operations practices and performance: A meta-analysis. International Journal of Productivity and Performance Management, 66(8), 1020-1042.Available at: https://doi.org/10.1108/ijppm-11-2015-0168.

Elzarka, S. (2020). A study on engaging employees in adopting green logistics practices: The case of logistics service providers in Egypt. International Journal of Logistics Systems and Management, 37(1), 140-152.Available at: https://doi.org/10.1504/IJLSM.2020.109669.

Fonsén, E., \& Soukainen, U. (2020). Sustainable pedagogical leadership in finnish early childhood education (ECE): An evaluation by ECE professionals. Early Childhood Education Journal, 48(2), 213-222.Available at: https://doi.org/10.1007/s 10643-019-00984-y.

Gazzola, P., Pezzetti, R., Amelio, S., \& Grechi, D. (2020). Non-financial information disclosure in Italian public interest companies: A sustainability reporting perspective. Sustainability, 12(15), 6063.Available at: https://doi.org/10.3390/su12156063.

Gold, N. O., \& Taib, F. M. (2020). Impact of corporate sustainability reporting practice on corporate performance: A review of literature. International Journal of Industrial Management, 8, 19-34.Available at: https://doi.org/10.15282/ijim.8.0.2020.5760.

Grewal, J., \& Serafeim, G. (2020). Research on corporate sustainability: Review and directions for future research. Foundations and Trends in Accounting, 14(2), 73-127.Available at: https://doi.org/10.1561/1400000061.

Hair Jr, J. F., Babin, B. J., \& Krey, N. (2017). Covariance-based structural equation modeling in the Journal of Advertising: Review and recommendations. Journal of Advertising, 46(1), 163-177.Available at: https://doi.org/10.1080/00913367.2017.1281777.

Hashom, H., Ariffin, A. S., Sabar, R., \& Ahmad, H. (2020). Halal-logistics value chain on firm performances: A conceptual framework. International Journal on Food, Agriculture and Natural Resources, 1(2), 8-14.Available at: https://doi.org/10.46676/ij-fanres.v 1i2.10.

Hörisch, J., Wulfsberg, I., \& Schaltegger, S. (2020). The influence of feedback and awareness of consequences on the development of corporate sustainability action over time. Business Strategy and the Environment, 29(2), 638-650.Available at: https://doi.org/10.1002/bse.2394.

Ishaq, M. I., \& Di Maria, E. (2020). Sustainability countenance in brand equity: A critical review and future research directions. Journal of Brand Management, 27(1), 15-34.Available at: https://doi.org/10.1057/s41262-019-00167-5.

Jain, H. (2020). andatory corporate social responsibility: A utilitarian and deontological perspective. Open Journal of Business and Management, 8(5), 2278-2284.Available at: https://doi.org/10.4236/ojbm.2020.85139.

Khan, A., Bibi, S., Lyu, J., Garavelli, A. C., Pontrandolfo, P., \& Perez Sanchez, M. d. A. (2020). Uncovering innovativeness in spanish tourism firms: The role of transformational leadership, OCB, firm size, and age. Sustainability, 12(10), 3989.Available at: https://doi.org/10.3390/su12103989.

Lăzăroiu, G., Ionescu, L., Andronie, M., \& Dijmărescu, I. (2020). Sustainability management and performance in the urban corporate economy: A systematic literature review. Sustainability, 12(18), 7705.Available at: https://doi.org/10.3390/su12187705.

Lesmana, R., Widodo, A. S., \& Sunardi, N. (2020). The formation of customer loyalty from brand awareness and perceived quality through brand equity of xiaomi smartphone users in South Tangerang. Journal of Competitive Marketing, 4(1), 1-12.

Loza, A. C. R. (2020). Sustainability reporting quality of peruvian listed companies and the impact of regulatory requirements of sustainability disclosures. Sustainability, 12(3), 1135.Available at: https://doi.org/10.3390/su12031135.

Meuer, J., Koelbel, J., \& Hoffmann, V. H. (2020). On the nature of corporate sustainability. Organization E Environment, 33(3), 319341.Available at: https://doi.org/10.1177/1086026619850180.

Moktadir, M. A., Dwivedi, A., Rahman, A., Chiappetta, J. C. J., Paul, S. K., Sultana, R., \& Madaan, J. (2020). An investigation of key performance indicators for operational excellence towards sustainability in the leather products industry. Business Strategy and the Environment, 29(8), 3331-3351.Available at: https://doi.org/10.1002/bse.2575.

Qian, W., Tilt, C., Dissanayake, D., \& Kuruppu, S. (2020). Motivations and impacts of sustainability reporting in the Indo-pacific region: Normative and instrumental stakeholder approaches. Business Strategy and the Environment, 29(8), 3370-3384.Available at: https://doi.org/10.1002/bse.2577.

Ren, R., Hu, W., Dong, J., Sun, B., Chen, Y., \& Chen, Z. (2020). A systematic literature review of green and sustainable logistics: Bibliometric analysis, research trend and knowledge taxonomy. International Journal of Environmental Research and Public Health, 17(1), 261.Available at: https://doi.org/10.3390/ijerph17010261.

Silvestre, W. J., \& Fonseca, A. (2020). Integrative sustainable intelligence: A holistic model to integrate corporate sustainability strategies. Corporate Social Responsibility and Environmental Management, 27(4), 1578-1590.Available at: https://doi.org/10.1002/csr.1906.

Soderstrom, S. B., \& Weber, K. (2020). Organizational structure from interaction: Evidence from corporate sustainability efforts. Administrative Science Quarterly, 65(1), 226-271.Available at: https://doi.org/10.1177/0001839219836670. 
Sudusinghe, J. I., \& Seuring, S. (2020). Social sustainability empowering the economic sustainability in the global apparel supply chain. Sustainability, 12(7), 2595.Available at: https://doi.org/10.3390/su12072595.

Sule, O. E., \& Onuoha, B. C. (2020). Sustainability strategy and service quality innovativeness of manufacturing firms in Ogun State. Asian Journal of Interdisciplinary Research, 3(1), 38-49.

Yahaya, R., \& Ebrahim, F. (2016). Leadership styles and organizational commitment: Literature review. The Journal of Management Development, 35(2), 190-2 16.Available at: https://doi.org/10.1 108/jmd-01-2015-0004.

Citation: Poomthan Thaenthao (2021). The Role of Brand Image Orientation, Innovativeness and Sustainability Marketing Commitment on Company Performance: Moderating Influence of Sustainable Leadership. Asian Business Research Journal, 6: 20-28. History:

Received: 23 March 2021

Revised: 5 July 2021

Accepted: 29 July 2021

Accepted: 29 July 2021
Published: 11 August 2021

Licensed: This work is licensed under a Creative Commons

Attribution 3.0 License (c) $\mathrm{E}$

Publisher: Eastern Centre of Science and Education

Eastern Centre of Science and Education is not responsible or answerable for any loss, damage or liability, etc. caused in relation to/arising out of the use of the content. Any queries should be directed to the corresponding author of the article.
Funding: This study received no specific financial support.

Competing Interests: The author declares that there are no conflicts of interests regarding the publication of this paper.

Transparency: The author confirms that the manuscript is an honest, accurate, and transparent account of the study was reported; that no vital features of the study have been omitted; and that any discrepancies from the study as planned have been explained.

Ethical: This study follows all ethical practices during writing.
study as lanned have been explained. 